\title{
INFLUÊNCIA DE DIFERENTES DOSES DE GESSO AGRÍCOLA SOBRE A PRODUTIVIDADE DA CULTURA DO TRIGO ( Triticum sativum L.)
}

Edison SCHIMIDT FILHO ${ }^{1}$

Francielli GASPAROTTO

Sonia TANIMOTO ${ }^{3}$

Thais de Oliveira Iacono RAMARI ${ }^{4}$

Maiko André ZANETTI ${ }^{4}$

${ }^{1}$ Dr, Professor Mestrado Tecnologias Limpas Unicesumar, edison.schmidt@ unicesumar.edu.br

2DDra, Professora Mestrado Tecnologias Limpas Unicesumar, francielli.gasasparotto@unicesumar.edu.br

${ }^{3}$ Dra, Professora Mestrado Tecnologias Limpas Unicesumar, sonia.tanimoto@unicesumar.edu.br

${ }^{4}$ Dra, Professora Mestrado Tecnologias Limpas Unicesumar, thaisiacono@yahoo.com.br

${ }^{5}$ Estudante de Agronomia Unicesumar, maikozanetti@ hotmail.com

Recebido em: 24/12/2015 - Aprovado em: 15/07/2016 - Disponibilizado em: 18/12/2016

\begin{abstract}
RESUMO
O gesso agrícola é um condicionante de solos que a cada ano vem sendo utilizado em maior escala na região de Maringá no Estado do Paraná. Tem com função contribuir para a eliminação ou redução do alumínio presente no solo em profundidade. Ainda, pode contribuir para a distribuição de nutrientes no perfil do solo de maneira mais homogênea e assim incrementar a produtividade de culturas como o trigo. Nesse contexto instalou-se um experimento de campo na Fazenda Escola da Unicesumar em Maringá PR com o objetivo de analisar a influência do gesso agrícola sobre a produtividade da cultura do trigo e distribuição de $\mathrm{P}, \mathrm{S}, \mathrm{Ca}, \mathrm{Mg}$ e $\mathrm{K}$ no perfil do solo melhorando as condições de cultivo e fertilidade. Foram testados cinco tratamentos com três repetições dispostos em Delineamento Inteiramente Casualizado (DIC): 0, 500, 1000, 1500 e $2000 \mathrm{~kg} \mathrm{ha}^{-1}$ de gesso agrícola. Para avaliar a influência da aplicação do gesso agrícola sobre os nutrientes estudados foram feitas duas coletas e análises de solo, antes da aplicação dos tratamentos e após a colheita do trigo cultivado, se mensurando assim os teores desses elementos. O solo da área experimental apresentava condições satisfatórias de fertilidade atendendo os limites necessários para o desenvolvimento fisiológico das plantas em comparação com o cultivo normalmente praticado a campo por produtores rurais da região. O tratamento de $2000 \mathrm{~kg} \mathrm{ha}^{-1}$ de gesso agrícola foi o que mais influenciou na cultura cultivada proporcionando um incremento na produtividade do trigo e grãos com melhor qualidade, com $\mathrm{PH}$ de 88,8 .
\end{abstract}

Palavras-chave: Produtividade do trigo. Peso Hectolitrico. Condicionante de solo. Perfil de solo. Gesso.

\begin{abstract}
The gypsum is a soil condition that each year has been used on a larger scale in Maringa region in the state of Paraná. It has to function contribute to the elimination or reduction of aluminum in the soil in depth. Still, it can contribute to the distribution of nutrients in the soil profile more uniformly and thus increasing the productivity of crops such as wheat. In this context settled a field experiment at the Farm School Unicesumar in Maringa PR with the aim of analyzing the influence of gypsum on the wheat crop productivity and distribution of $\mathrm{P}, \mathrm{S}, \mathrm{Ca}, \mathrm{Mg}$ and $\mathrm{K}$ in the soil profile improving the conditions of cultivation and fertility. Five treatments were tested with three replicates arranged in Delineation Completely Randomized (DIC): 0, 500, 1000, 1500 and $2000 \mathrm{~kg}$ ha -1 of gypsum. To evaluate the influence of application of gypsum on the nutrients studied were made two collections and soil analysis before application of treatments and after harvest of wheat grown, thus measuring the levels of these elements. The soil of the experimental area had favorable conditions of fertility given the limits required for the physiological development of plants compared to the cultivation usually practiced field for farmers in the region. Treatment of $2000 \mathrm{~kg}$ ha -1 of gypsum that has most influenced the culture cultivated providing a increase in wheat yield and grain with better quality PH 88.8.
\end{abstract}

Keywords: Wheat Productivity. Hectoliter weight. Condition of soil. Soil profile. Gypsum. 


\section{INTRODUÇÃO}

A cultura do trigo no Brasil teve seu inicio pelo sul do país, por meio dos imigrantes europeus (principalmente por italianos e alemães). Esses imigrantes introduziram no Brasil o contexto de produção e comercialização local, entretanto a produção de trigo obteve seu destaque no estado do Paraná, na década de 1970 (CUNHA 1999). O Brasil produzia naquela época aproximadamente seis milhões de toneladas sendo que $50 \%$ da produção eram provenientes do sul do país (principalmente do Paraná) e a produtividade alcançada naquele período estava em torno de $1894 \mathrm{~kg}$ ha $^{-1}$ (BASSOI, 2013).

$\mathrm{O}$ trigo vem perdendo destaque no cenário agrícola paranaense face os valores de mercado praticados nas ultimas safras e a expansão do milho safrinha na região norte do Paraná. Assim, a cultura tem se tornado menos atraente para investidores do ramo agrícola. Ainda, o trigo é tido como cultura de alto risco para sua produção e comercialização inclusive ficando sem cotação para comercialização em algumas épocas do ano (AGRIANUAL, 2014).

Com o avanço dos estudos sobre a fertilidade de solos para cultivos agrícolas, o uso de tecnologias como um condicionante de solo se torna fator importante para contribuir para incrementar a absorção de nutrientes $\mathrm{P}, \mathrm{S}$, $\mathrm{Ca}, \mathrm{Mg}$ e $\mathrm{K}$ e água. O gesso agrícola atua na neutralização do $\mathrm{Al}^{+^{3}}$, proporcionando maior crescimento para o sistema radicular e possibilitando que as raízes atinjam camadas superiores a $20 \mathrm{~cm}$ de profundidade no perfil do solo, gerando vários benefícios à cultura e consequentemente maior resistência a períodos de estiagem. (ORIVALDO A. et al., 1999).

A origem do gesso se da pelo sulfato de cálcio obtido como subproduto do acido fosfórico, utilizado na fabricação de fosfatos de amônia como MAP e DAP e super fosfato triplo. A cada tonelada de acido fosfórico, é gerada cerca de quatro toneladas de gesso (MALUF 2009). Este produto é usado na melhoria do ambiente radicular em profundidade, proporciona uma alta mobilidade na camada arável do solo, fixando-se abaixo dessa camada, permitindo o aprofundamento de raízes e uma melhor exploração dos nutrientes aplicados ao solo (SOUZA et al., 2005). E, segundo Costa (2006) o gesso agrícola além contribuir para uma melhora no ambiente que geralmente é pouco favorável às raízes, contribui também para o aumento de concentrações de alguns nutrientes como $\mathrm{S}$ e $\mathrm{Ca}$ no solo (COSTA 2006).

Nesse contexto o objetivo foi avaliar a influencia de diferentes doses de gesso agrícola na fertilidade do solo, quanto aos nutrientes $\mathrm{P}, \mathrm{S}, \mathrm{Ca}, \mathrm{Mg}$ e $\mathrm{K}$, a contribuição para a produtividade da cultura do trigo e o Peso Hectolitrico dos grãos colhidos. 


\section{MATERIAL E MÉTODOS}

$\mathrm{O}$ experimento foi instalado em uma área da Fazenda Unicesumar - BIOTEC, no município de Maringá no estado do Paraná, cujas coordenadas geográficas são: latitude $23^{\circ} 20^{\prime} 44.25^{\prime \prime S}$ e longitude 5152'23.35" O e altitude de 509 metros. O cultivo anterior À pesquisa na área experimental foi com a cultura da mandioca entre os anos de 2012 a 2014.

Previamente à instalação do experimento a área foi dessecada para controlar a emergência de plantas invasoras. As parcelas foram locadas a campo medindo 3,0 metros de largura por 5,0 metros de comprimento, com área total de $15 \mathrm{~m}^{2}$.

O experimento foi composto por cinco tratamentos, T1 sem a adição de gesso agrícola, T2 com $500 \mathrm{~kg} \mathrm{ha}^{-1}$, T3 com 1000 $\mathrm{kg} \mathrm{ha}{ }^{-1}, \mathrm{~T} 4$ com $1500 \mathrm{~kg} \mathrm{ha}^{-1}$ e T5 que recebeu $2000 \mathrm{~kg} \mathrm{ha}^{-1}$ de gesso agrícola. A composição média do gesso utilizado foi de $17 \%$ de cálcio; $14 \%$ de enxofre e $22 \%$ de oxido de cálcio.

A aplicação do gesso agrícola foi realizada superficialmente sem incorporação e dois dias antes da semeadura, de acordo com os tratamentos realizados.

Foi utilizado uma cultivar de ciclo precoce, CD 154 da empresa COODETEC. A semeadura ocorreu no dia 08 de maio de 2015. A densidade de semeadura foi de 80 sementes por metro linear com espaçamento entrelinhas de 17 centímetros, obtendo-se 400 sementes $\left(\mathrm{m}^{2}\right)^{-1}$. Todos os tratametnos receberam a aplicação de $330 \mathrm{~kg} \mathrm{ha}^{-1}$ do formulado 4-20-20 (N-P-K).

Os tratos culturais foram realizados em todos os tratamentos e sob as mesmas condições de forma a minimizar possíveis influências relacionadas ao manejo da cultura a campo, incluindo os tratamentos fitossanitários recomendados para a cultura do trigo.

A colheita do trigo cultivado na área experimental foi realizada no na segunda quinzena do mês de agosto de 2015. Nessa operação foram excluídas duas linhas laterais e coletadas manualmente as espigas das linhas centrais das parcelas, totalizando $4,8 \mathrm{~m}^{2}$ de área colhida.

As sementes do trigo colhido foram levadas ao laboratório para as avaliações de rendimento de produtividade, Peso Hectolitrico (PH) e umidade.

A fertilidade do solo na área experimental foi avaliada antes da aplicação dos tratamentos e após a colheita do trigo cultivado. As coletas de solo foram feita nas 15 parcelas nas profundidades de 0 a 20 centímetros e de 20 a 40 centímetros. As análises foram realizadas no laboratório de solos da Unicesumar para

Os dados mensurados para cada parâmetro avaliado foram organizados para cada tratamento e comparados entre si. Foi feita análise estatística e os dados foram submetidos à análise de variância com 
significância pelo teste de Skot Knot ao nível de $5 \%$ de probabilidade.

\section{RESULTADOS E DISCUSSÃO}

Após o ciclo vegetativo da cultura a campo, os grãos foram colhidos e a produtividade comparada entre todos os tratamentos. O resultado da produtividade está apresentado na figura 1 que mostra a comparação entre os tratamentos para as produtividades obtidas no experimento, variando de 0 a $2000 \mathrm{~kg} \mathrm{ha}^{-1}$.

FIGURA 1: Média de produtividade de trigo colhido em cada parcela em função dos tratamentos realizados com gesso agrícola em $\mathrm{kg} \mathrm{ha}^{-1}$.

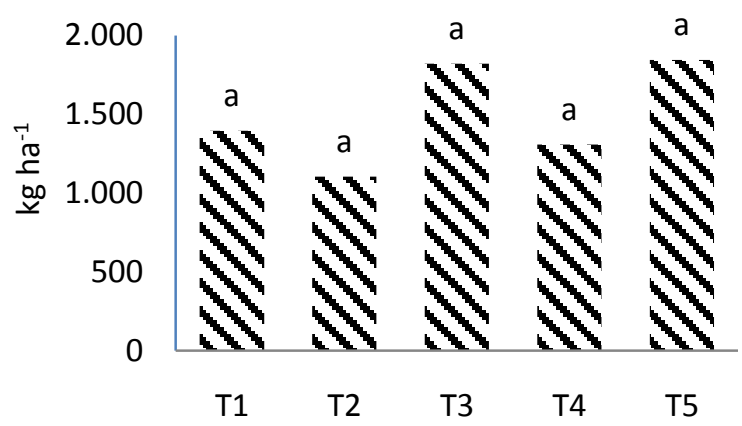

* Para cada coluna, as médias seguidas de mesmas letras não diferem entre si pelo teste de Skot Knot no nível de $5 \%$ de probabilidade.

Fonte: Laborfort, 2015.

A aplicação de doses crescentes de gesso agrícola solo da área cultivada não influenciou significativamente na produtividade de trigo para todos os tratamentos realizados. Dessa forma não foi detectada uma expressão da diferença estatística sobre as doses alternadas em todas as parcelas experimentais. De acordo com Kurihara (2012), o gesso é considerado um condicionante que apresenta o seu efeito no solo em longo prazo quando aplicado em superfície, até que seja carreado para profundidades maiores ao longo do tempo pela ação da água da chuva.

O tratamento que teve o melhor resultado sobre a produtividade do trigo foi o de numero cinco (T5). Penckowsk (2009) diz que a produtividade esta altamente relacionada ao tipo de manejo empregado e a quantidade de insumos dispostas para o desenvolvimento da cultura. Como todos os tratamentos foram conduzidos sob o mesmo manejo e com a mesma quantidade de fertilizantes aplicados, pode-se inferir que o gesso apresentou, no caso desse tratamento, alguma influência sobre a produtividade. No entanto sem significância estatística.

FIGURA 2: Média dos teores de $\mathrm{P}, \mathrm{S}, \mathrm{Ca}, \mathrm{Mg}$ e $\mathrm{K}$ no solo a profundidade de 0 a $20 \mathrm{~cm}$ após a colheita do trigo.

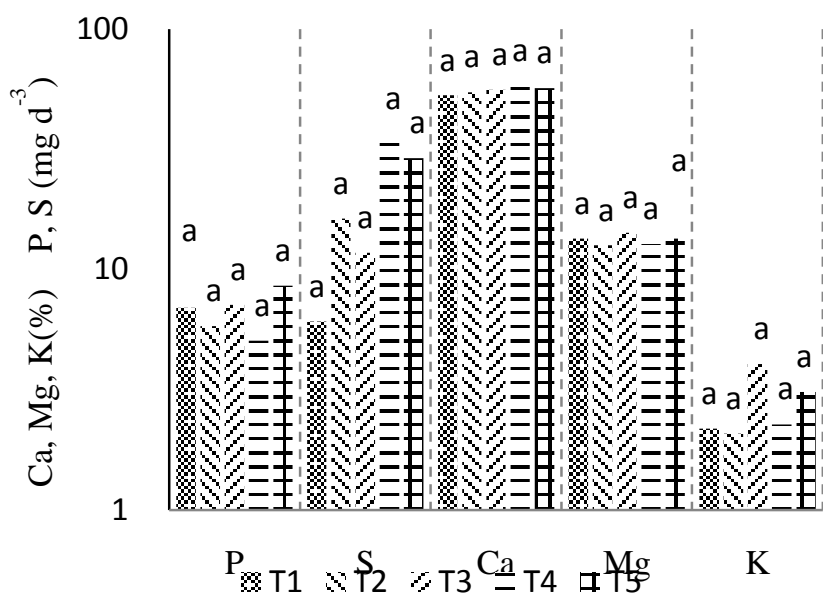

\footnotetext{
* Para cada coluna, as médias seguidas de mesmas letras não diferem entre si pelo teste de Skot Knot no nível de $5 \%$ de probabilidade.

Fonte: Laborfort, 2015.
} 
A figura 2 apresenta os teores dos macronutrientes encontrados na amostragem de solo de 0-20 centímetros de profundidade.

Em relação à fertilidade de solo nenhum nutriente expressou diferença estatística sobre os demais nutrientes expostos para o estudo. Segundo Malavolta (2002), a adubação tem a finalidade de fornecer o que a planta necessita, portanto o uso de adubação se faz necessário e muito importante para o desenvolvimento da cultura, Pessoni (2012), portanto o gesso tem grande influencia no ambiente radicular, fazendo melhorar esse aspecto no solo.

O elemento fósforo $(\mathrm{P})$ não teve uma expressão significativa para os demais nutrientes, portanto o tratamento cinco (T5) expressou uma baixa elevação no teor do nutriente. Os teores de fósforo $(\mathrm{P})$ variam de quase 0 a $10 \mathrm{mg} \mathrm{dm}^{-3}$, portanto o fósforo só tem fontes para sua elevação produtos fosfatados como superfosfato simples ou superfosfato triplo Troeh et al. (2007).

$\mathrm{O}$ enxofre (S) por sua vez não demonstrou uma expressão significativa perante aos seus dados obtidos, porém pode se notar um leve incremento nos tratamentos quatroe cinco (T4 - T5), se destacando dos demais tratamentos avaliados. De acordo com Borin (2011), no cultivo de algodão com a adição de gesso agrícola, não contribui para a alteração da fertilidade, sem haver alteração significativa para o macronutriente enxofre no solo.
Já o nutriente cálcio (Ca), não teve elevação na sua concentração no solo, se manteve estável para todos os tratamentos, porém Sávio (2011) destaca que por mais que o gesso forneça cálcio no perfil do solo não ocorre alteração nos teores de cálcio em respostas as diferentes doses de gesso em solo.

Juntamente com o cálcio e os demais nutrientes, o elemento magnésio $(\mathrm{Mg})$ não apresentou uma significância estatística, em relação a testemunha. Pode ter ocorrido um leve arrastamento no teor de magnésio no solo nos tratamentos dois e quatro (T2 e T4). Isso é confirmado por Malavolta (2002) quando diz que, dependendo do solo onde foi aplicado o gesso e a quantidade usada, pode ocorrer o arrastamento de magnésio $(\mathrm{Mg})$ juntamente com o potássio (K) para a sub superfície.

$\mathrm{O}$ nutriente potássio $(\mathrm{K})$ por sua vez também não teve diferença estatística dos demais nutrientes avaliados, porem pode-se notar um aumento nos tratamentos três e cinco (T3 - T5) para esse nutriente. Troeh et al.(2007) relatam que o potássio pode ser arrastado para a sub superfície, e isso pode ser acelerado com o uso do gesso agrícola. Os teores de potássio (K) não apresentaram diferenças estatísticas sobre os outros tratamentos. Ocorreu um aumento no teor no solo com o tratamento três (T3), e uma diminuição no tratamento dois (T2). Os demais tratamentos se mantiveram iguais à 
testemunha (T1) o que confirma Ernani (1986) quando observou que até o uso de $32 \mathrm{t}$ $\mathrm{ha}^{-1}$, o teor de potássio não foi alterado no solo.

A figura 3 apresenta os teores médios dos nutrientes que foram obtidos em análise do solo coletado a profundidade de 20 a 40 centímetros para cada parcela do campo experimental em função dos tratamentos testados. Esses resultados expressam os valores após a colheita do trigo a campo.

FIGURA 3:Média dos teores de P, S, Ca, Mg e K no solo a profundidade de20 a $40 \mathrm{~cm}$ após a colheita do trigo.

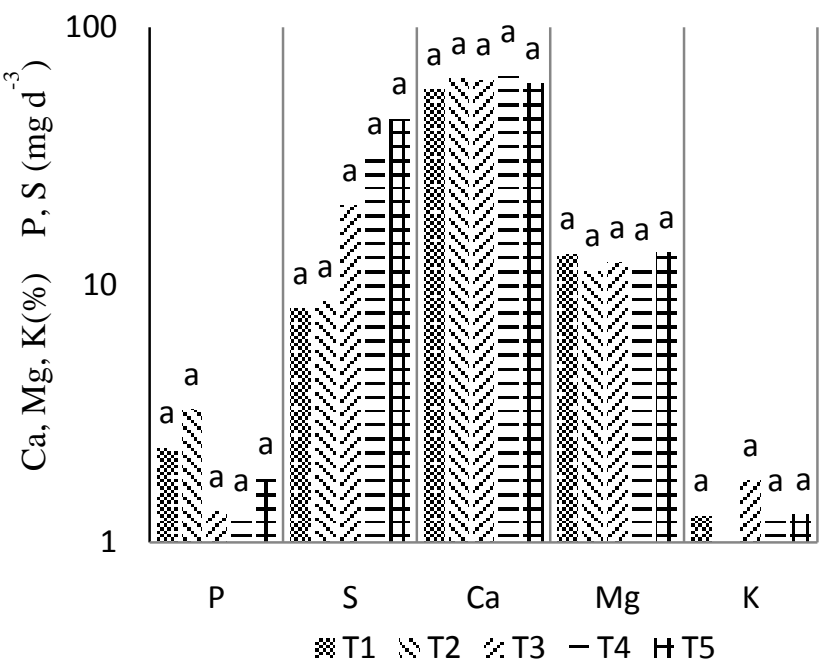

* Para cada coluna, as médias seguidas de mesmas letras não diferem entre si pelo teste de Skot Knot no nível de $5 \%$ de probabilidade.

Fonte: Laborfort, 2015.

Como era esperado, o fósforo foi o que apresentou menor quantidade no solo amostrado. Isso indica que o gesso agrícola não contribuiu para o incremento dos teores desse nutriente no solo uma vez que se trata de característica química comumente encontrada em solos da região de Maringá, apresentando baixos teores de P.

$\mathrm{O}$ macro nutriente fósforo $(\mathrm{P})$ analisado na profundidade de 20-40 centímetros, teve um decréscimo em comparação a testemunha, somente o tratamento dois apresentou um leve acréscimo sobre os demais tratamentos analisados. De acordo com Vetti (2005), solo em regiões tropicais e subtropicais, o elemento fósforo $(\mathrm{P})$ apresenta teores baixos, e em profundidades como de 20-40, podendo tender a zero $\mathrm{mg} \mathrm{dm}^{-3}$.

O nutrientes fósforo, cálcio, magnésio e potássio não expressaram diferença estatística, somente o enxofre teve diferença estatística sobre os demais dados.

O elemento enxofre (S) não apresentou diferença estatística em comparação entre os tratamentos. Porén, segundo Vetti (2005) um dos motivos de se usar o gesso agrícola, é que ele pode ser usado como fonte de cálcio e enxofre. Alvarez et al. (2007), afirma que quando o gesso agrícola aplicado em quantidades adequadas ele resulta em um acréscimo do elemento enxofre (S) no solo em longo prazo.

A concentração de cálcio (Ca) apresentado na figura 2 , não diferenciou da testemunha (T1), apresentado apenas um leve incremento nos tratamentos dois, três e quatro (T2 - T3- T4). Esse resultado não indicou que pode influenciar sobre a fertilidade do solo uma vez que a contribuição foi muito baixa. De acordo com Costa (2007), o efeito da 
gessagem não influenciou os teores de nutrientes do cálcio, já Caires et al. (2003) aborda que o gesso tem o poder de aumentar os níveis de cálcio no solo.

Quando se compara o teor inicial de magnésio $(\mathrm{Mg})$ na testemunha (T1), percebe se uma menor quantidade do nutriente nos demais tratamentos. Isso denota de o gesso ter uma ação maior de arrasto do magnésio $(\mathrm{Mg})$ por ele conter cargas positivas maiores que os outros nutrientes. Segundo Ramos (2013), a aplicação de gesso proporciona o arrastamento de nutrientes com maior facilidade como o magnésio ( $\mathrm{Mg}$ ) para maiores profundidades.

\section{CONCLUSÃO}

Em textura muito argilosa, como no caso do solo de Maringá PR onde o experimento foi conzuido, não se constatou influências significativas.

Nas condições desse experimento, a avaliação de produtividade da cultura do trigo não foi influenciada pelo gesso agrícola para que ocorresse um aumento significativo na produção. Na fertilidade de solo nas duas profundidades amostradas não apresentaram efeito significativo, podendo destacar que o gesso não tem uma ação direta a curto prazo, como foi o desenvolvimento do trabalho.

\section{AGRADECIMENTOS}

A UNICESUMAR e a meu orientador que contribuíram para que a pesquisa fosse realizada e pelo suporte e tempo dispensados para as orientações e incentivos.

\section{REFERÊNCIAS}

AGRIANUAL 2014 - Anuário da agricultura brasileira. São Paulo, SP, 2014. $447 \mathrm{p}$.

ALVAREZ, V, G.; NOVAIS, R, F.; BARROS, N, F.; FONTES, R, L.; CANTARUTTI, R, B.; NEVES, J, C, L. Fertilidade do solo. Viçosa - MG,2007.

BASSOI M.C. et al. Cultivares de Trigo Embrapa e Iapar. Embrapa Soja, Londrina PR, 2013.

BORIM, A. C; SMIRDERLE, O. J; OLIVEIRA, M, C.M; SOUZA, F. G; BARBOSA, R. R; calagem e gessagem de solo cultivado com algodão no cerrado de Roraima. Embrapa algodão. Boa Vista. RO, 2011.

CAIRES, E.F., et al. Alterações de características químicas do solo e resposta da soja ao calcário e gesso aplicados na superfície em sistema de cultivo sem preparo do solo. Universidade Estadual de Ponta Grossa, Ponta Grossa - PR, 1998. CAIRES, E.F. et al. Alterações químicas do solo e resposta da soja ao calcário e gesso aplicados na implantação do sistema plantio direto. Rev. Bras. Cienc. Solo, Campinas, v. 27, n. 2, p. 275-86, 2003.

COSTA, M. J. Manejo de solo e efeito residual da gessagem sobre atributos físicos e químicos de um latossolo vermelho distroférrico e no desenvolvimento da soja. Dissertação (Mestrado em Produção Vegetal), Universidade Federal do Mato Grosso do Sul, Dourados, MS, 2006.

COSTA, M. J .; JUNIOR, E. J. R.; ROSA, Y. B. C. J.; SOUZA, L. C. F.; ROSA, C. B. J. 
Atributos químicos e físicos de um Latossolo sendo influenciados pelo manejo do solo e efeito da gessagem. Maringá, PR, 2007.

CUNHA, G.R., org. Trigo, 500 anos no Brasil. Passo Fundo: Embrapa Trigo, 1999.

ERNANI, P.R. Alterações em algumas características químicas na camada arável do solo pela aplicação de gesso agrícola sobre a superfície de campos nativos. Rev. Bras. Cienc. Solo, Viçosa, v. 10, n. 3, p. 241245, 1986.

KURIHARA, C. H, TSUJIGUSHI, B. C, SILVA, J. S, SOARES, R. B, Resposta de milho safrinha consorciado com brachiaria ruziziensis à calagem, gessagem e ao manejo da adubação (safras 2011 e 2012). Aquidauana, MS, 2012.

MALAVOLTA, E.; GOMES, F.P.; ALCARDE, J.C. Adubos \& Adubações. São Paulo, SP, 2002. 84 p.

MALUF, H. J. G. M.; CAMPOS, D. S.; MELO, P. F.; MALUF, G. E. G. M. Gesso agrícola em solos do Cerrado brasileiro. Instituto Federal de Educação, Ciência e Tecnologia Minas Gerais (IFMG), Bambuí, MG, 2009.

ORIVALDO A., et al. Efeitos na cultura do trigo da rotação com milho e adubos verdes, na presença e na ausência de adubação nitrogenada. UNESP, Campinas SP, 1999.

PENCKOWSKI, L. H.; ZAGONEL, J.; FERNANDES, E. C. Nitrogênio e redutor de crescimento em trigo de alta produtividade. Maringá, PR, 2009.

PESSONI, P.T. Calagem e gessagem na produtividade da soja e do triticale. Dissertação (Mestrado em Agricultura Tropical e Subtropical) Instituto Agronômico, Campinas, SP, 2012.
RAMOS, B. Z.; TOLEDO, J. P. V. F.; LIMA J. M.; SERAFIM, M. E.; BASTOS, A. R. R.; GUIMARÃES, P. T.G.; COSCIONE, A.R. Doses de gesso em cafeeiro: Influência nos teores de cálcio, magnésio, potássio e pH na solução de um latossolo vermelho distrófico. R. Bras. Ci. Solo, 2013.

SÁVIO, F.L; SILVA, G. C; TEIXEIRA, I. R; MOTA, J. H; BORÉM, A; Calagem e gessagem na nutrição e produção de soja em solo com pastagem degradada. Piracicaba, SP, 2011.

SOUSA de D.M.G., LOBATO E., REIN T.A. Uso de Gesso Agrícola nos Solos do Cerrado. Circular Técnica 32, Embrapa, Planaltina - DF, 2005.

TROEH, R, F.; TOMPSON, L. M. Solos e Fertilidade do solo. São Paulo, SP, 2007. 351 - $381 \mathrm{p}$.

VETTI, G, C 2005.Manual de fertilidade de solo. São Paulo, SP, 2005. 85 p. 